\title{
Comment on: Pathologic Response to Preoperative Chemotherapy in Colorectal Liver Metastases: Fibrosis, Not Necrosis, Predicts Outcome
}

\author{
Hector H. Li-Chang, MD, FRCPC ${ }^{1}$ and David K. Driman, MBChB, FRCPC ${ }^{2}$ \\ ${ }^{1}$ Deparment of Laboratory Medicine and Pathobiology, Mount Sinai Hospital, University of Toronto, Toronto, ON, \\ Canada; ${ }^{2}$ Department of Pathology, Western University, London, Canada
}

\section{TO THE EDITORS:}

We read with interest the article by Poultsides et al. ${ }^{1}$ entitled "Pathologic Response to Preoperative Chemotherapy in Colorectal Liver Metastases: Fibrosis, Not Necrosis, Predicts Outcome." The authors showed that the amount of necrosis in metastases was not associated with improved disease survival in the univariate analysis because it was seen in similar proportions in both treated and untreated tumors.

Findings have shown that the histologic response of colorectal liver metastases to perioperative chemotherapy is of prognostic significance. In this setting, treatment with bevacizumab has been associated with improved tumor regression and outcomes, ${ }^{2}$ as well as with increased tumour necrosis. ${ }^{3}$ This suggests that tumor necrosis represents a positive response to treatment. Paradoxically, necrosis also is a feature seen commonly in metastases that have not responded to treatment or have not received any treatment. ${ }^{4}$

About the same time this work was published, we presented data suggesting that "sporadic" necrosis (i.e., that found in tumors not responding chemotherapy) can be distinguished from necrosis secondary to treatment, which we termed "infarct-like necrosis" (ILN). ${ }^{5}$ We defined criteria to distinguish ILN from sporadic necrosis. The article by Poultsides et al. includes a good example of ILN in Fig. $1 b .{ }^{1}$ In our series, ILN was associated with bevacizumab treatment and seen only in patients treated with perioperative chemotherapy. Furthermore, responders to

\section{(C) Society of Surgical Oncology 2017}

First Received: 20 October 2017;

Published Online: 27 November 2017

H. H. Li-Chang, MD, FRCPC

e-mail: hector.hugo.li@gmail.com therapy (stratified by outcome) could be more readily distinguished from non-responders when this histologic form of necrosis was considered a form of treatment effect (i.e., equivalent to fibrosis).

We suggest that ILN is a form of treatment response in colorectal liver metastases with prognostic equivalence to fibrosis. Failure to classify ILN as a form of treatment effect could result in underestimation of therapy response. Therefore, identifying this form of necrosis is important for pathologists evaluating treatment effect in both clinical and research settings.

DISCLOSURE None.

\section{REFERENCES}

1. Poultsides GA, Bao F, Servais EL, et al. Pathologic response to preoperative chemotherapy in colorectal liver metastases: fibrosis, not necrosis, predicts outcome. Ann Surg Oncol. 2012;19:2797804.

2. Gruenberger T, Arnold D, Rubbia-Brandt L. Pathologic response to bevacizumab-containing chemotherapy in patients with colorectal liver metastases and its correlation with survival. Surg Oncol. 2012;21:309-15.

3. Klinger M, Tamandl D, Eipeldauer S, et al. Bevacizumab improves pathological response of colorectal cancer liver metastases treated with XELOX/FOLFOX. Ann Surg Oncol. 2010;17:2059-65.

4. Rubbia-Brandt L, Giostra E, Brezault C, et al. Importance of histological tumor response assessment in predicting the outcome in patients with colorectal liver metastases treated with neoadjuvant chemotherapy followed by liver surgery. Ann Oncol. 2007;18:299-304.

5. Chang HHL, Leeper WR, Chan G, Quan D, Driman DK. Infarctlike necrosis: a distinct form of necrosis seen in colorectal carcinoma liver metastases treated with perioperative chemotherapy. Am J Surg Pathol. 2012;36:570-6. 